\title{
Design and fabrication of heart muscle using scaffold-based tissue engineering
}

\author{
Nicole R. Blan, ${ }^{1}$ Ravi K. Birla ${ }^{2}$ \\ ${ }^{1}$ Deparment of Chemical Engineering, University of Michigan, Ann Arbor, Michigan 48109 \\ ${ }^{2}$ Section of Cardiac Surgery, University of Michigan, Ann Arbor, Michigan 48109
}

Received 16 February 2007; revised 11 June 2007; accepted 26 June 2007

Published online 30 October 2007 in Wiley InterScience (www.interscience.wiley.com). DOI: 10.1002/jbm.a.31642

\begin{abstract}
Cardiac tissue engineering strategies are based on the development of functional models of heart muscle in vitro. Our research is focused on evaluating the feasibility of different tissue engineering platforms to support the formation of heart muscle. Our previous work was focused on developing three-dimensional (3D) models of heart muscle using self-organization strategies and biodegradable hydrogels. To build on this work, our current study describes a third tissue engineering platform using polymer-based scaffolding technology to engineer functional heart muscle in vitro. Porous scaffolds were fabricated by solubilizing chitosan in dilute glacial acetic acid, transferring the solution to a mold, freezing the mold at $-80^{\circ} \mathrm{C}$ followed by overnight lyophilization. The scaffolds were rehydrated in sodium hydroxide to neutralize the $\mathrm{pH}$, sterilized in $70 \%$ ethanol and cellularized using primary cardiac myocytes. Several variables were studied: effect of polymer concentration and chitosan solution volume (i.e., scaffold thickness) on scaffold fabrication, effect of cell number and time in culture on active force generated by cardiomyocyte-seeded scaffolds and the effect of lysozyme on scaffold degradation. Histology (hematoxylin and eosin) and contractility (active, baseline and specific force, electrical pacing) were evaluated for the cellularized constructs under different conditions. We found that a polymer concentration in the range $1.0-2.5 \%(\mathrm{w} / \mathrm{v})$ was most suitable for scaffold fabrication while a scaffold thickness of $200 \mu \mathrm{m}$ was optimal for cardiac cell functionality. Direct injection of the cells on the scaffold did not result in contractile constructs due to low cell retention.
\end{abstract}

Fibrin gel was required to retain the cells within the constructs and resulted in the formation of contractile constructs. We found that lower cell seeding densities, in the range of 1-2 million cells, resulted in the formation of contractile heart muscle, termed smart material integrated heart muscle (SMIHMs). Chitosan concentration of $1-2 \%$ $(\mathrm{w} / \mathrm{v})$ did not have a significant effect on the active twitch force of SMIHMs. We found that scaffold thickness was an important variable and only the thinnest scaffolds evaluated $(200 \mu \mathrm{m})$ generated any measurable active twitch force upon electrical stimulation. The maximum active force for SMIHMs was found to be $439.5 \mu \mathrm{N}$ while the maximum baseline force was found to be $2850 \mu \mathrm{N}$, obtained after 11 days in culture. Histological evaluation showed a fairly uniform cell distribution throughout the thickness of the scaffold. We found that lysozyme concentration had a profound effect on scaffold degradation with complete scaffold degradation being achieved in $2 \mathrm{~h}$ using a lysozyme concentration of $1 \mathrm{mg} / \mathrm{mL}$. Slower degradation times (in the order of weeks) were achieved by decreasing the lysozyme concentration to $0.01 \mathrm{mg} / \mathrm{mL}$. In this study, we provide a detailed description for the formation of contractile 3D heart muscle utilizing scaffoldbased methods. We demonstrate the effect of several variables on the formation and culture of SMIHMs. (C) 2007 Wiley Periodicals, Inc. J Biomed Mater Res 86A: 195-208, 2008

Key words: chitosan; cardiac cells; fibrin; tissue engineering; contractile function

\section{INTRODUCTION}

Tissue engineering strategies are based on the assumption that patient-derived cells expanded in culture maintain differentiated phenotype and can

Correspondence to: R.K. Birla, Biomedical Science Research Building, 109 Zina Pitcher Place, Rm. 2018, Ann Arbor, MI 48109-2200, USA; e-mail: rbirla@umich.edu

Contract grant sponsor: Section of Cardiac Surgery, University of Michigan

(C) 2007 Wiley Periodicals, Inc. be utilized to engineer functional three-dimensional (3D) tissue constructs. ${ }^{1,2}$ Translating this definition to cardiac tissue engineering necessitates the utilization of patient-derived primary cells to re-engineer cardiovascular structures. Although cell sourcing remains a critical challenge for cardiac applications, the applicability of tissue engineered heart muscle would be far reaching. Such tissue engineering methodology could be utilized in translating twodimensional monolayer cell cultures to more physiological 3D tissue engineered constructs. Potential applications for 3D tissue engineered constructs would be in high throughput drug screening and 
clinically as patches to augment failing myocardial function. ${ }^{3}$ There have been several models of functional 3D muscle utilizing different platforms for tissue engineering. ${ }^{4-26}$

Our previous work has focused on developing functional models of cardiac muscle in vitro. ${ }^{27-29}$ Our first tissue engineering model for cardiac muscle was based on the self-organization of primary cardiac myocytes on laminin-coated surfaces with anchor points engineered at various points. ${ }^{27}$ Primary cardiac cells were plated at a high density on tissue culture surface coated with an adhesion protein. This resulted in the formation of cohesive cell monolayer, exhibiting a high degree of spontaneous contractions for the duration of the culture. Contractions of the cell monolayer promote detachment from the underlying culture surface. Subsequent remodeling resulted in the formation of contractile 3D heart muscle, termed cardioids. The most attractive feature of the cardioid model is the formation of 3D heart muscle in the absence of any synthetic scaffolding material in the contractile region of the tissue construct.

The major limiting factor in the utility of the cardioid model was the extended time period required for tissue formation; 2-3 weeks after initial cell plating. To address this concern, we evaluated the feasibility of utilizing fibrin gel as a support matrix for cardiac muscle formation. ${ }^{30}$ We found that utilization of fibrin greatly decreased the time required for the formation of tissue constructs to less than one week. ${ }^{30}$ The resulting tissue constructs, termed bioengineered heart muscle (BEHMs), also exhibited a higher active force compared to cardioids. The higher forces were likely due to the presence of fibrin to support heart muscle formation; cardioids may require additional interventions to promote the formation of extracellular matrix to increase the active force. Other groups have also shown the feasibility of utilizing fibrin for cardiac tissue engineering applications. ${ }^{31,32}$

In these previous two studies, we have demonstrated the feasibility of using self-organization strategies as well as biodegradable hydrogels to promote the formation of contractile heart muscle in vitro. We found the each model provided unique advantages and critical technological challenges. As our work progressed, we understood the need to evaluate different tissue engineering platforms for heart muscle. The "dominant design" for heart muscle has yet to be identified and may prove to be either one of our platforms or contain elements from each of them; it may very well be something totally different. To build on our previous work, in this study, we were interested in evaluating the feasibility of utilizing a polymeric scaffold to support heart muscle formation in vitro. One additional motivation for this study was to compare scaffold-based methods to our previously published models; insight can be gained by comparing the three tissue engineering platforms side by side.

We selected chitosan as the biomaterial for this study because of several properties making it suitable for cardiac tissue engineering applications. Chitosan is the partially de-acetylated derivative of chitin and consisting of $\beta(1-4)$ linked D-glucosamine residues $^{33}$ found in arthropod (such as crab and shrimp) exoskeletons. The $\mathrm{pH}$ dependent solubility of chitosan has provided a convenient mechanism for polymer processing under mild conditions and allowed the fabrication of porous scaffolds, ${ }^{34}$ planar membranes, ${ }^{35}$ and hydrogels. ${ }^{36}$ Chitosan shares structural homology to glycoaminoglycans and has a hydrophilic surface, ${ }^{37}$ thereby making it suitable for specific interactions with growth factors, receptors, and adhesion proteins.

Chitosan has fairly well-characterized degradation kinetics. $^{38}$ In vivo chitosan membranes can be degraded by macrophages within 12 weeks while in vitro, the degradation rate can be accelerated by controlling enzyme concentration and can be as fast as $4-5$ days. ${ }^{39}$ The biocompatibility of chitosan has also been the focus of several investigations ${ }^{40,41}$ and chitosan has been shown to be nonthrombogenic, ${ }^{42}$ eliciting minimal foreign body response ${ }^{40}$ and can safely be eliminated from the body. ${ }^{41}$

The various desirable properties of chitosan have made it a suitable material for tissue engineering applications and chitosan has been utilized in der$\mathrm{mal}^{43}{ }^{43}$ neural, ${ }^{44}$ cartilage, $^{36,37}$ bone, ${ }^{45-47}$ vascular, liver, ${ }^{48-50}$ pancreas, ${ }^{51}$ and cardiac ${ }^{52,53}$ tissue engineering applications. There have been no published reports of the utility of chitosan for cardiac tissue engineering applications. The purpose of this study was to evaluate the feasibility of utilizing chitosan as a biomaterial to support the formation of contractile 3D heart muscle in vitro.

\section{MATERIALS AND METHODS}

NIH guidelines for the care and use of laboratory animals (NIH Publication \#85-23 Rev. 1985) have been observed. All materials were purchased from Sigma (St. Louis, MO) unless otherwise specified.

\section{Isolation of neonatal cardiac myocytes}

Cardiac myocytes were isolated from 2 to 3-day-old F344 rat hearts using an established method. ${ }^{54}$ Hearts were cut into fine pieces and suspended in a dissociation solution (DS) that consisted of $0.32 \mathrm{mg} / \mathrm{mL}$ collagenase type II (Worthington Biochemical, Lakewood, NJ) and $0.6 \mathrm{mg} / \mathrm{mL}$ pancreatin dissolved in a buffer consisting of $116 \mathrm{mM}$ 


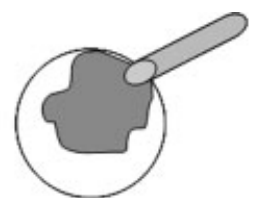

A. Chitosan poured into mold

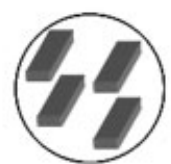

D. Scaffolds are cut to size needed and re-hydrated to neutralize the acid.

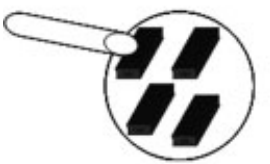

G. Fibrin is added to the scaffold to complete the gelling method to ensure the cells adhere to the scaffold.

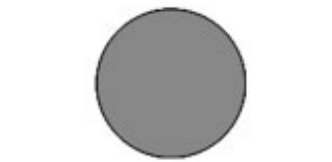

B. Frozen at -80 degrees Celsius

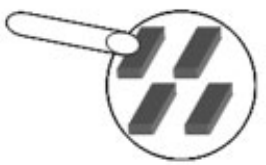

E. Fibrinogen is added to scaffold to begin the gelling process.

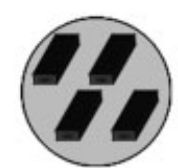

H. The completed scaffold in cardiac media.

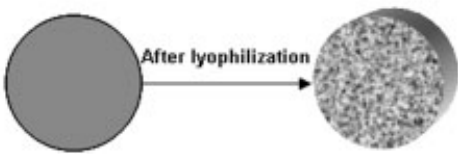

C. The planar scaffolds are lyophilized overnight to remove the $\mathrm{H}_{2} \mathrm{O}$ crystals through sublimation leaving behind a 3-D porous scaffold.

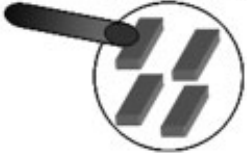

F. Cardiac myocytes are added to the thrombin covered scaffolds.

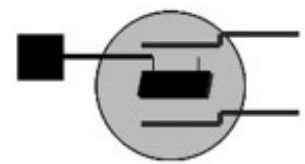

L. The active force is evaluated by stimulating the scaffold with platinum electrodes and an optical force transducer to measure force.

Figure 1. Overview of methodology. A-D: Chitosan is poured into a mold, frozen at $-80^{\circ} \mathrm{C}$ and lyophilized, resulting in the formation of a porous 3D scaffold, which can be cut into any shape or size. E-H: Thrombin is added to the scaffolds, followed by primary cardiac myocytes suspended in DMEM and fibrinogen. The scaffolds are allowed to sit in a cell culture plate for 5-10 min, followed by the addition of culture media. I: The contractile properties of the cellularized scaffolds are evaluated by providing a pulse stimulus utilizing platinum electrodes. The force of contraction is recorded by optical force transducers.

$\mathrm{NaCl}, 20 \mathrm{mM}$ HEPES, $1 \mathrm{mM} \mathrm{Na} \mathrm{HPO}_{4}, 5.5 \mathrm{mM}$ glucose, $5.4 \mathrm{mM} \mathrm{KCl}$, and $0.8 \mathrm{mM} \mathrm{MgSO}_{4}$. Digestion was carried out in an orbital shaker for $5 \mathrm{~min}$ at $37^{\circ} \mathrm{C}$, after which the supernatant was replaced with fresh DS and the digestion process was continued for an additional $30 \mathrm{~min}$. At the end of the digestion process, the supernatant was collected in $5 \mathrm{~mL}$ of horse serum (Invitrogen, Auckland, New Zealand), centrifuged at $1500 \mathrm{rpm}$ for $5 \mathrm{~min}$ and the cell pellet was resuspended in $5 \mathrm{~mL}$ horse serum. Fresh DS was added to the original, undigested tissue and the digestion process was repeated for an additional 2-3 times. Cells from all the digests were pooled, centrifuged and then suspended in culture medium consisting of $320 \mathrm{~mL}$ M199, $100 \mathrm{~mL} \mathrm{F12k,} 50 \mathrm{~mL}$ fetal bovine serum, $25 \mathrm{~mL}$ horse serum, $5 \mathrm{~mL}$ antibiotic-antimycotic (Invitrogen, Auckland, New Zealand), hydrocortisone $40 \mathrm{ng} / \mathrm{mL}$ and insulin $100 \mathrm{ng} / \mathrm{mL}$. No pre-plating was utilized for the primary isolate and the cells were utilized as obtained after the isolation procedure. Based on our previous experience, the cell viability is in excess of $90 \%$, determined $24 \mathrm{~h}$ after cell plating using the MTT assay.

\section{Fabrication of scaffolds}

Chitosan scaffolds were fabricated according to a previously described method. ${ }^{34}$ Chitosan (Catalog \# 4-00559, Carbomer, San Diego, CA) was solubilized in $1 \%$ glacial acetic acid at the desired concentration for $24 \mathrm{~h}$ with continuous mixing at room temperature [Fig. $1(\mathrm{~A}-\mathrm{C})]$. The chitosan solution was then transferred to 35-mm cell culture plates coated with polydimethylsiloxane [Fig. 1(A)] and then frozen at $-80^{\circ} \mathrm{C}$ for $1 \mathrm{~h}$ [Fig. 1(B)]. The frozen samples were lyophilized overnight [Fig. 1(C)]. The dried samples were carefully removed from the cell culture plates and cut into rectangular sections $15 \mathrm{~mm}$ long and $5 \mathrm{~mm}$ wide [Fig. 1(D)]. The samples were rehydrated in $0.1 \mathrm{M} \mathrm{NaOH}$ for $30 \mathrm{~min}$, then samples were washed in PBS three times and sterilized in $70 \%$ for $1 \mathrm{~h}$ and then stored in PBS until use.

The chitosan concentration was varied between $0.5 \%$ and $3.0 \%(\mathrm{w} / \mathrm{v})$ with increments of $0.5 \%$. Five scaffolds were fabricated at each chitosan concentration by transferring $2 \mathrm{~mL}$ of solution into $35-\mathrm{mm}$ tissue culture plates. At each concentration, the solubility of the chitosan was evaluated by visually evaluating the amount of particulate material after a $24-\mathrm{h}$ mixing period. In addition, the viscosity of the solutions at the different chitosan concentration was noted based on the ease of solution handling and the ability to use a standard pipette for solution transfer.

The thickness of the scaffold was varied between 200 and $1000 \mu \mathrm{m}$ with increments of $200 \mu \mathrm{m}$ by changing the volume of chitosan that was poured into each mold. Six scaffolds were fabricated at each of the five thicknesses $(200,400,600,800$, and $1000 \mu \mathrm{m})$ using each of the six chitosan concentrations $(0.5 \%, 1.0 \%, 1.5 \%, 2.0 \%, 2.5 \%$, and $3.0 \%$ ) for a total of 180 scaffolds (Table I). The thickness was measured using digital calipers. Our functional endpoint for all of these scaffolds was the ability of the polymer solution to support the formation of $3 \mathrm{D}$ scaf- 
TABLE I

Experimental Design-Parameters Evaluated for the Current Study

\begin{tabular}{|c|c|c|c|c|c|c|c|c|}
\hline \multirow{2}{*}{$\begin{array}{c}\text { Chitosan } \\
\text { Concentration (\%) }\end{array}$} & \multirow{2}{*}{$\begin{array}{c}\text { Scaffold } \\
\text { Thickness }(\mu \mathrm{m})\end{array}$} & \multicolumn{3}{|c|}{$\begin{array}{c}\text { Degradation Kinetics, } \\
\text { Lysozyme Concentration } \\
(\% \mathrm{v} / \mathrm{v} \text { in PBS })\end{array}$} & \multicolumn{3}{|c|}{$\begin{array}{l}\text { Cellularization Using } \\
\text { Fibrin Gel Method and Direct } \\
\text { Injection (No. of Cells/Scaffold) }\end{array}$} & \multirow[b]{2}{*}{ Time Course Study } \\
\hline & & 0.01 & 0.1 & 1 & $1 \times 10^{6}$ & $2 \times 10^{6}$ & $5 \times 10^{6}$ & \\
\hline 0.5 & $\begin{array}{r}200 \\
400 \\
600 \\
800 \\
1000\end{array}$ & & & & & & & \\
\hline 1.0 & $\begin{array}{r}200 \\
400 \\
600 \\
800 \\
1000\end{array}$ & & & & & & & \\
\hline 1.5 & $\begin{array}{r}200 \\
400 \\
600 \\
800 \\
1000\end{array}$ & & & & & & & \\
\hline 2.0 & $\begin{array}{r}200 \\
400 \\
600 \\
800 \\
1000\end{array}$ & & & & & & & \\
\hline 2.5 & $\begin{array}{r}200 \\
400 \\
600 \\
800 \\
1000\end{array}$ & & & & & & & \\
\hline 3.0 & $\begin{array}{r}200 \\
400 \\
600 \\
800 \\
1000\end{array}$ & & & & & & & \\
\hline
\end{tabular}

Chitosan scaffolds were prepared using six different polymer concentrations $(0.5 \%, 1.0 \%, 1.5 \%, 2.0 \%, 2.5 \%$, and $3.0 \%)$ and five different thicknesses $(200,400,600,800$, and $1000 \mu \mathrm{m})$. Our initial evaluation was based on the ability to support the formation of three-dimensional scaffolds. The degradation kinetics was evaluated for a subset of the scaffolds using two different lysozyme concentrations $(0.01$ and $0.1 \mathrm{mg} / \mathrm{mL})$. The change in scaffold weight was evaluated at multiple time points during a 7-day interval. The cellularization studies were conducted for scaffolds fabricated using 1 and $2 \%$ chitosan with a thickness of 200,600, and $1000 \mu \mathrm{m}$. For each of these conditions, two cellularization methods (direct injection vs. fibrin gel) and three seeding densities (1, 2, and $5 \times 10^{6}$ cells/scaffolds) were evaluated at a single time point, 7 and 14 days postcellularization. The twitch force in response to electrical stimulation was evaluated for the cellularized scaffolds. Gray bars represent conditions that were tested; $n=3-6$ for each group.

folds. This was evaluated by solubility of the polymer in $1 \%$ glacial acetic acid and the macroscopic properties of the 3D scaffold.

\section{Degradation kinetics}

We conducted a pilot study utilizing three lysozyme (derived from chicken egg white) concentrations $(1.0 \%$, $0.1 \%$, and $0.01 \% \mathrm{v} / \mathrm{v}$ in PBS) and followed the degradation kinetics of chitosan scaffolds fabricated using a polymer concentration of 1 and $2 \%$ at three thicknesses (200, 600, and $1000 \mu \mathrm{m}$ ) (Table I). The degradation of the scaffolds was followed over a 1-week time period with three time points in between. The dry weight of the scaffold (normalized to the initial scaffold weight) was used to quantify the rate of degradation. Based on the results of these pilot studies, we defined two degradation regimes, rapid and slow, based on the time required for completed scaffold degradation from hours to weeks (discussed further in the "Results" and "Discussion" sections). Rapid degradation studies were conducted using scaffolds fabricated with polymer concentrations of 1,2 , and $3 \%$ at thicknesses of 200, 600, and $1000 \mu \mathrm{m}$ (Table I). Because of the fact that complete scaffold degradation was accomplished within 2$6 \mathrm{~h}$, our data acquisition was limited to obtaining high-resolution digital images of the scaffolds at incremental time points during the degradation period. 
For our second set of studies, we utilized scaffolds fabricated with a polymer concentration of $1.0 \%, 1.5 \%$, and $2.0 \%$ with thicknesses of 200, 400, 600, 800, and $1000 \mu \mathrm{m}$ and a lysozyme concentration of $0.01 \%$ (Table I). Every scaffold was placed in an independent $35-\mathrm{mm}$ tissue culture plate and $2 \mathrm{~mL}$ of the diluted enzyme was added to the plate. At incremental time points, the scaffolds were removed from the lysozyme solution, washed in PBS, airdried for $2 \mathrm{~h}$ and then weighed. As controls, PBS was added to two groups 1.0 and $2.0 \%$ chitosan using thicknesses of 200 and $1000 \mu \mathrm{m}$. Scaffolds were weighed every 2-3 days over a 2-week period with $n=3$ for each group.

\section{Cellularization of scaffolds}

We evaluated two cellularization strategies to support heart muscle formation: direct inject of cardiac cells and utilization of a fibrin gel. For the first method of direct injection, the primary cardiac cells were suspended in culture media and directly injected onto the surface of the scaffold. A volume of $50 \mu \mathrm{L}$ was used per scaffold and cell concentrations of 1,2 , and 5 million cells/scaffold were used. We utilized a $100-\mu \mathrm{L}$ micropipette to transfer the cells directly on to the surface of the scaffold. The cells were allowed to settle for a period of $1 \mathrm{~h}$ in an incubator and then $2 \mathrm{~mL}$ of culture media was added to each plate; the scaffolds were cultured in standard $35-\mathrm{mm}$ cell culture plates with four scaffolds/plate.

For our second method using the fibrin gel, the primary cardiac cells were suspended in culture media containing $10 \mathrm{U} / \mathrm{mL}$ of thrombin. Fibrinogen $(25 \mu \mathrm{L}$ of $20 \mathrm{mg} / \mathrm{mL})$ was added to each scaffold and allowed to penetrate into the scaffolds for $15 \mathrm{~min}$ [Fig. 1(E)]. This suspension $(25 \mu \mathrm{L})$ (cardiac cells in culture media with thrombin) was added to the scaffolds (pre-soaked in fibrinogen) [Fig. 1(F)]. An additional $10 \mu \mathrm{L}$ of $20 \mathrm{mg} / \mathrm{mL}$ fibrinogen was added to each scaffold to complete the gellation process [Fig. 1(G)]. The process of gel formation continued for $15 \mathrm{~min}$ after which $2 \mathrm{~mL}$ of culture media was added to each culture plate. Three cell concentrations were used; 1,2 , and 5 million cells/scaffold.

For the cellularization studies, scaffolds were fabricated using two chitosan concentrations (1 and $2 \%$ ) and three scaffold thicknesses $(200,600$, and $1000 \mu \mathrm{m})$ (Table I). The twitch force of the cellularization scaffold in response to electrical stimulation was evaluated after 7 days in culture. Culture media consisted of 320 mL M199, 100 mL F12k, $50 \mathrm{~mL}$ fetal bovine serum, $25 \mathrm{~mL}$ horse serum and $5 \mathrm{~mL}$ antibiotic-antimycotic (Invitrogen, Auckland, New Zealand).

A time course study was performed with a single group of scaffolds using both cellularization methods. A chitosan concentration of $1 \%$ was utilized with a scaffold thickness of $200 \mu \mathrm{m}$. We used $n=3$ for each group and four time points at 4, 6, 8, and 11 days postcellularization for both methods. A total of 72 scaffolds were used for the cellularization studies with 36 scaffolds used for each of the two cellularization methods. All 72 scaffolds were used for force testing. Based on the results of the force testing, additional scaffolds were cellularized to evaluate the histological properties. Three scaffolds were used at each cell concentration (1, 2, and 5 million cells/scaffold) and the histological properties evaluated after 11 days in culture.

The scaffolds that were used for histological evaluation were different from the scaffolds that were force tested. Force data were obtained for all three scaffolds at the specified time points whereas histological data were only obtained at the terminal time point (11 days). The scaffolds used for this study were $200 \mu \mathrm{m}$ thick and were fabricated using $1 \%$ chitosan solution in glacial acetic acid.

Controls for our cellularization studies were prepared by adding fibrinogen and thrombin to the scaffolds in the absence of any cells. The active force of the controls was evaluated at a single time point (after 4 days in culture). We did not evaluate the pacing characteristics, timedependant changes in active force and histological data for the controls. A total of six controls were prepared.

\section{Evaluation of contractility}

The method for evaluating the contractility of tissue engineered cardiac muscle has been described in detail. ${ }^{27}$ Briefly, the construct was placed in culture media at $37^{\circ} \mathrm{C}$ between parallel platinum electrodes. One end was fixed to the plate and the other end was attached to a custombuilt optical force transducer [Fig. 1(I)]. The active twitch force (response to a single electrical impulse) measurements were then recorded at $5 \mathrm{~V}$, with a frequency of $1 \mathrm{~Hz}$ and a 10-ms pulse width. The active twitch force was generated in response to the contraction and relaxation of the cells within the construct. The baseline force of the constructs was also recorded. The baseline force was due to the construct, in the absence of any contractions by the cells. The magnitude of the twitch active force was used to determine the functionality of the cellularized scaffold. The scaffold was considered to be "functional" when the twitch active force was significantly greater than noise $(>3-4 \mu \mathrm{N})$. The length of each construct was adjusted to obtain maximum stimulated active force using a multiaxis micromanipulator. This optimal length was designated as $L_{\mathrm{o}}$ and was recorded. The cross-sectional area was calculated from the dimensions of the construct (length $\times$ width $\times$ thickness). The specific force $\left(\mathrm{kN} / \mathrm{m}^{2}\right)$ of the constructs was determined by normalizing the active force to the total crosssectional area. Initial stimulation parameters were selected based on our previous experience with engineered cardiac muscle constructs. The stimulation parameters had been optimized for this system in pilot experiments. The constructs were electrically paced at frequencies between 1 and $7 \mathrm{~Hz}$, with all other stimulation parameters remaining constant.

\section{Histology}

Constructs were fixed in $4 \%$ paraformaldehyde for $4 \mathrm{~h}$ and stored in $70 \%$ ethanol. The constructs were prepared in an automated tissue processor (Shandon Hypercenter $\mathrm{XP}$, Thermo Electron, Waltham, MA) and then paraffin embedded. Seven micron sections were cut and placed on Probeon Plus slides (Fisher Scientific, Pittsburg, PA). He- 
matoxylin and eosin staining was used for morphologic analysis of the constructs.

\section{Scanning electron microscopy}

Scanning electron microscopy (SEM) was utilized to validate the pore size of the scaffolds formed in this study. The samples were placed on a metal stub and coated with graphite at the contacting ends. The samples were dried in a vacuum desiccator for $6 \mathrm{~h}$ and then sputter-coated with gold using a Polaron E5100 Sputter Coater. SEM was performed using an AMRAY 1000-B scanning electron microscope at an accelerating voltage of $3 \mathrm{kV}$. The scaffold surface directly in contact with the freezing surface was utilized for SEM analysis. We selected three representative scaffolds from a single batch of lyophilized constructs for SEM analysis; all three scaffolds were fabricated using $2 \%$ chitosan at a thickness of $600 \mu \mathrm{m}$. Each scaffold was cut into multiple sections using a razor blade and all sections were imaged. The pore diameter was determined for selected images using the onboard image analysis software. We obtained representative images for all three scaffolds and measured the pore diameter for 3-5 pores/ image. A total of 15 pores were used to determine the mean and standard deviation. Representative images were selected for publication.

\section{Statistical analysis}

We used one-way ANOVAs combined with the Tukey's test for all pair-wise comparisons. Minitab V13.31 (State College, PA) was used for statistical analysis.

\section{RESULTS}

\section{Scaffold fabrication}

The fabrication of chitosan scaffolds was dependant on the polymer concentration and volume of polymer solution per mold. At polymer concentrations of $0.5 \%$ to $2.5 \%$, complete solubilization of the polymer was achieved in $1.0 \%$ glacial acetic acid after a 24-h mixing period. However, at the highest polymer concentration test, $3.0 \%$, un-dissolved particles were visible after mixing for $24 \mathrm{~h}$ in glacial acetic acid. At the lower end, scaffolds fabricated with $0.5 \%$ chitosan were fragile, prone to physical damage in response to gentle handling and had a nonuniform surface texture. Based on these observations, we selected a range of $1.0 \%-2.5 \%$ as our working concentration for scaffold fabrication. Scaffold thickness was easily controlled by changing the volume of polymer solution per mold. Using 35- $\mathrm{mm}$ cell culture plates and $0.5-3.0 \mathrm{~mL}$ of solution, we were able to fabricate scaffolds with thicknesses of 200-1000 $\mu \mathrm{m}$. SEM analysis showed that the average pore diameter was $51 \pm 12 \mu \mathrm{m}(n=15)$ (Fig. 2).
A.

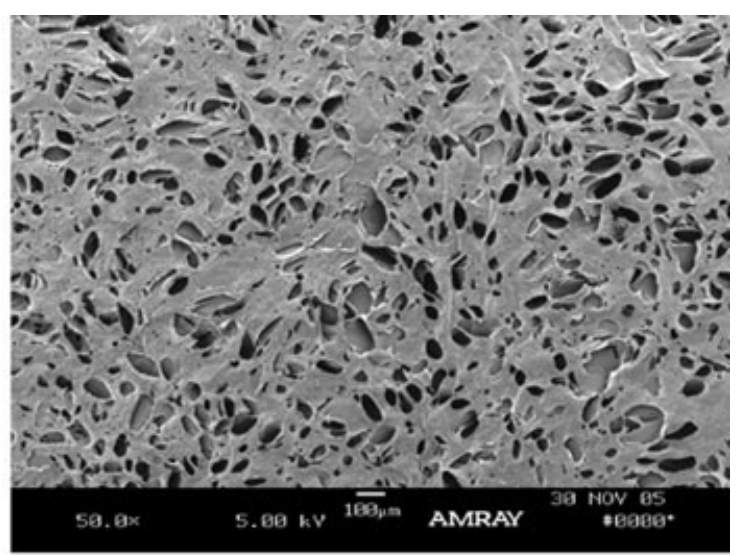

B.

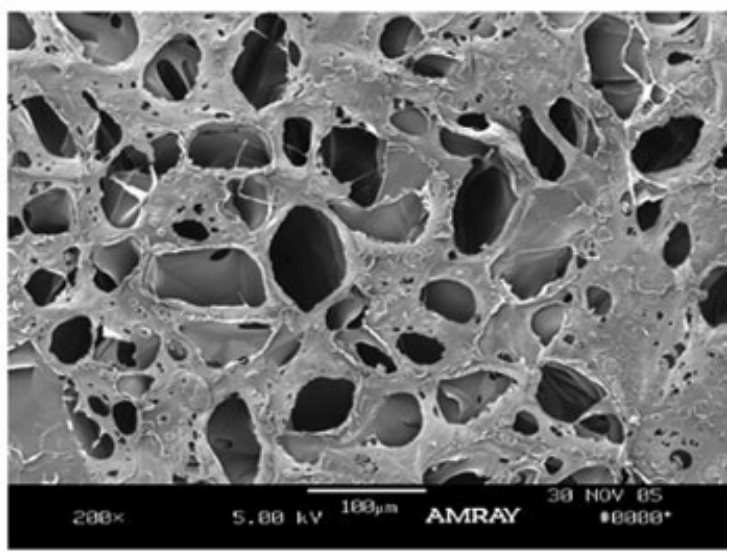

C.

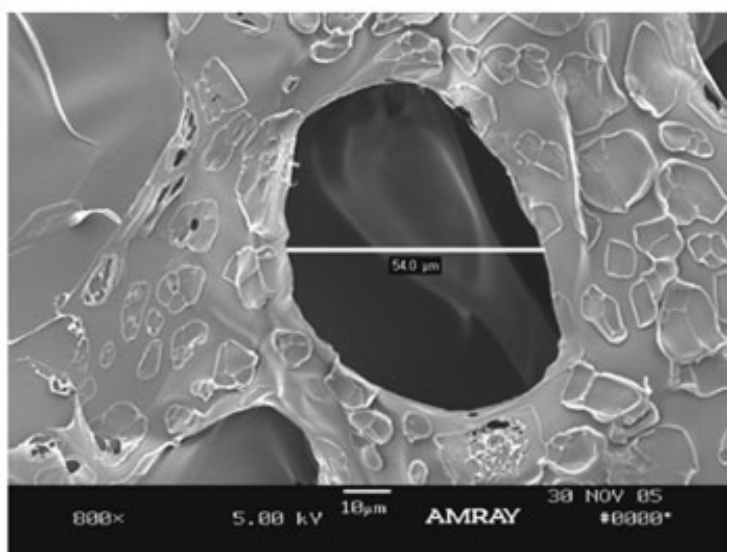

Figure 2. SEM analysis of scaffolds. Images were obtained for the surface of the scaffold which was in contact with dry ice. A: Low-magnification $(\times 50)$ images were obtained to show the uniform distribution of the pores. B: Higher magnification $(\times 200)$ images were obtained to show the detailed architecture and depth of the pores. C: Images obtained at $\times 800$ showed that the average diameter was $\sim 50 \mu M$. The images shown are representative of images obtained at multiple sites for three scaffolds.

\section{Degradation kinetics}

The properties of the chitosan scaffold were affected by varying the concentration of lysozyme, thickness of the scaffold, and the concentration of polymer used for scaffold fabrication (Fig. 3). Variations in polymer thickness had no effect on the degradation time at any 


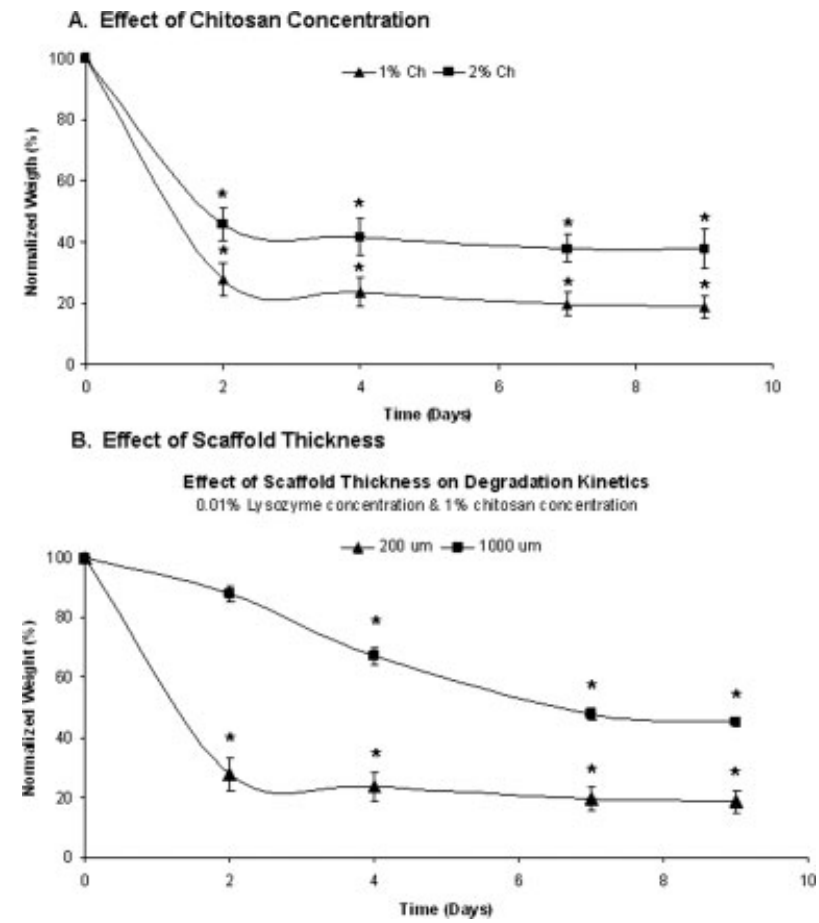

Figure 3. Degradation Kinetics. The effect of chitosan concentration and scaffold thickness on the rate of degradation was evaluated. A: Effect of chitosan concentrationscaffolds were fabricated utilizing 1 and $2 \%$ chitosan. B: Effects of chitosan thickness-scaffolds were fabricated at different thicknesses and subjected to lysozyme degradation. For all groups, lysozyme at a concentration of $0.1 \%$ was added to the scaffolds and the degradation kinetics followed over time. At the specified time points, multiple scaffolds were air-dried for $2 \mathrm{~h}$ and then weighed. For each time point, $n=4$ and the error bars represent standard deviations. *Denotes a statistical difference in scaffold weight when compared with the weight at time zero with $p<0.5$.

of the polymer concentrations. We were able to accomplish slower degradation of the scaffolds using a lysozyme concentration of $0.1 \%$. The rate of scaffold degradation was the slowest using a polymer concentration of $2 \%$ with a scaffold thickness of $1000 \mu \mathrm{m}$ [Fig. 3(A)]. Under these conditions, only $15 \%$ of the scaffold was degraded in $48 \mathrm{~h}$ and $55 \%$ degraded by day 9 [Fig. 3(A)]. The rate of scaffold degradation was the fastest using a polymer concentration of $1 \%$ with a scaffold thickness of $200 \mu \mathrm{m}$ [Fig. 3(A)]. Under these conditions, $73 \%$ of the scaffold had degraded with $48 \mathrm{~h}$ and $82 \%$ degraded by day 9 . At any given polymer concentration, increasing the thickness of the scaffold resulted in delaying the rate of degradation [Fig. 3(B)]. The rate of degradation within the first $48 \mathrm{~h}$ was found to be variable. Rapid degradation (possibly due to surface degradation) within the first $48 \mathrm{~h}$ was followed by a decrease during the remaining time period; possibly due to substrate (chitosan) depletion or bulk degradation. On the contrary, slow degradation within the first $48 \mathrm{~h}$ was followed by a fairly linear degradation rate; proportional to the amount of available substrate or due to a fairly uniform bulk degradation [Fig. 3(A,B)]. Utilizing a lysozyme concentration of $1.0 \%$, complete degradation of the scaffold was complete in 2-6 h, depending on the thickness and the polymer concentration.

\section{Scaffold cellularization}

We evaluated two different methods for the cellularization of scaffolds; direct injection of the cells and utilization of a fibrin gel. Direct injection of the cardiac cells resulted in a large number of cells outside the scaffolds, evaluated using an inverted microscope showing a fairly large body of cells directly surrounding the scaffolds. Increasing the number of cardiac cells from 1 to 5 million per scaffold resulted in a proportional increase in the number of cells observed outside the scaffold. Scaffolds that were cellularized by direct injection did not generate any measurable twitch force upon electrical stimulation at any of the time points tested (data not shown). Histological evaluation of the scaffolds demonstrated that only a few cells were visible throughout the scaffolds, even at different thicknesses throughout the scaffolds (data not shown).

Utilization of fibrin gel to support the cellularization of the scaffolds had a profound effect on the ability of cardiac cells to remain within the scaffolds. Utilization of fibrin greatly reduced the number of cells observed in proximity to the scaffolds in culture, promoted cell retention and produced constructs that generated active force. Macroscopical evaluation suggested cell retention during cell culture. Histological evaluation demonstrated the presence of cells at different thicknesses of the scaffold (Fig. 4). The presence of the chitosan scaffold was clearly visible in the histological images as well.

Polymer concentration, scaffold thickness, and seeding density were shown to have an effect on the contractile properties of the cellularized scaffolds (Fig. 5). We found that only scaffolds with a thickness of $200 \mu \mathrm{m}$ generated any measurable active twitch force upon electrical stimulation [Fig. 5(A)]. We also found that an initial seeding density of $1 \times 10^{6}$ to $2 \times 10^{6}$ cells per scaffold did not result in any measurable differences in the active twitch force [Fig. 5(B)]. Similarly, polymer concentration of $1-2 \%(\mathrm{w} / \mathrm{v})$ did not result in any significant changes in active twitch force in response to electrical stimulation [Fig. 5(C)].

Based on the time course study, we found that the maximum active force was achieved after 8-11 days in culture (Fig. 6). After 8 days in culture, the maximum active force was found to be $56.7 \pm 3.9 \mu \mathrm{N}$ $(n=3)$, and $70.5 \pm 2.6 \mu \mathrm{N}(n=3)$ after 11 days in 


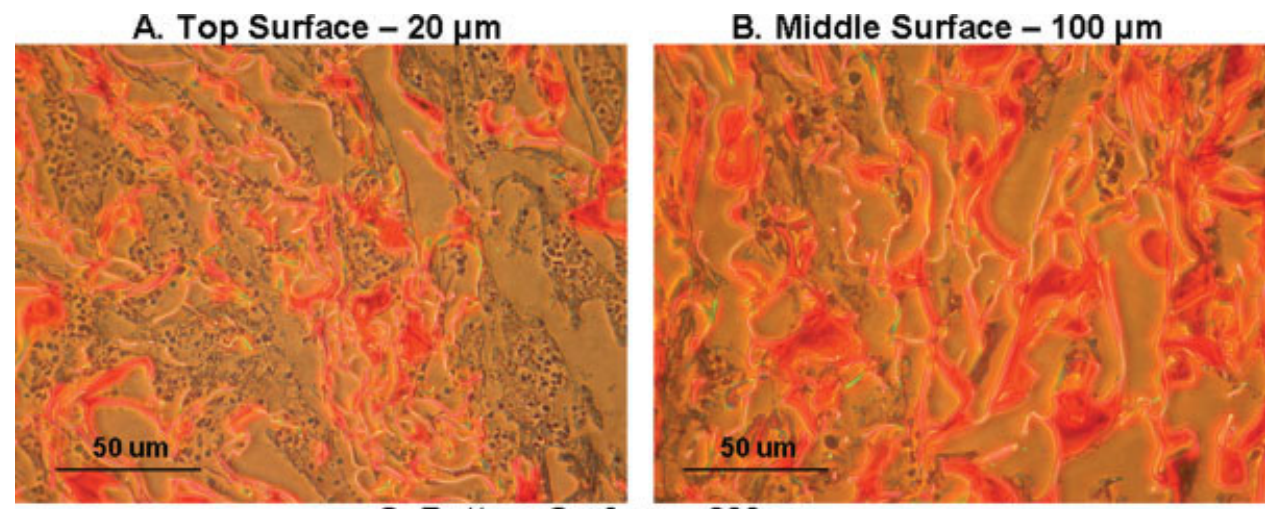

C. Bottom Surface $-200 \mu \mathrm{m}$

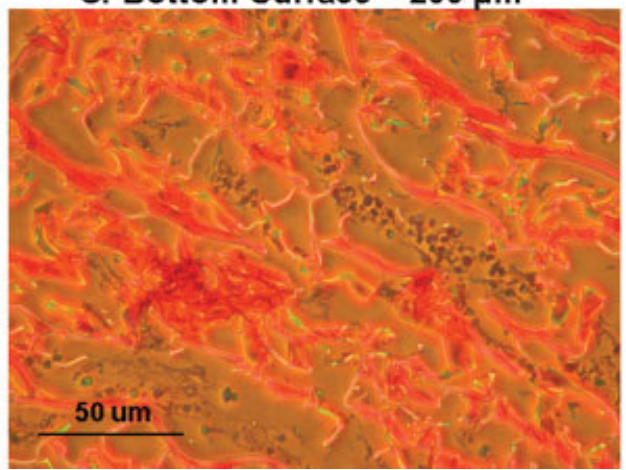

Figure 4. Histological validation of scaffold cellularization. Serial sections were obtained for the cellularized chitosan scaffolds after 2 weeks in culture. A seeding density of 2 million cells per scaffold was used. Scaffolds were fabricated using $1 \%$ chitosan in glacial acetic acid. The scaffolds were $200 \mu \mathrm{m}$ thick. Sections were obtained at $10 \mu M$ increments. Slides were stained with hematoxylin and eosin. A: Top surface-refers to the surface on which the cardiac cells were added. A very large number of cells can be observed to be uniformly distributed throughout the scaffold. B: Middle surface-at the center of the scaffold, the number of cells is lower than the number of cells on the top surface. However, there appears to be a fairly large number of cells still present at the center of the scaffold. The cells do appear to be fairly uniformly distributed throughout the scaffold. C: Bottom surface-the distribution of the cells was similar to the distribution of the cells at the center of the scaffold. In all cases, the scaffold stains a distinctive pink color making it fairly easy to identify. In addition, we observed that the fiber orientation and pore distribution was distorted in most of the slides used for histological evaluation. This was very likely a result of the sectioning of the slides using a cryostat. [Color figure can be viewed in the online issue, which is available at www.interscience.wiley.com.]

culture (Fig. 6). Initial force production was low prior, during the 6 days of culture. The active twitch force increased after 8 days in culture and reached a maximum at 11 days. The constructs were termed smart material integrated heart muscle (SMIHM). For the remainder of this article, the cellularized constructs will be termed SMIHMs.

\section{Contractile behavior of SMIHMs}

The maximum active force that was obtained for SMIHMs fabricated using a polymer concentration of $1 \%$, a scaffold thickness of $200 \mu \mathrm{m}$ and a plating density of 1 million cells, was found to be $439.5 \mu \mathrm{N}$ with a baseline force of $2850 \mu \mathrm{N}$ [Fig. 7(A)]. Interestingly, we also observed a very high degree of spontaneous contractions in the SMIHMs, often lasting for days in culture. Although high forces were routinely achievable using our cellularization methodology, there were often batches of SMIHMs that gener- ated considerable lower active forces, typically in the range of $100 \mu \mathrm{N}$, possibly due to batch variability in cells. Controls, generated in the absence of any cells, did not generate any measurable force upon electrical stimulation [Fig. 7(B)].

In addition to the active twitch force, we were able to electrically pace the SMIHMs at frequencies ranging from 1 to $7 \mathrm{~Hz}$. The SMIHMs did exhibit some degree in twitch force during electrical pacing (Fig. 8). When paced at a frequency of $3 \mathrm{~Hz}$, the maximum active force was found to be 378.4 and $329.6 \mu \mathrm{N}$ at a frequency of $5 \mathrm{~Hz}$ : the decrease in active force was recoverable after resting (Fig. 9). The baseline force increased in response to continuous electrical pacing of SMIHMs (Fig. 9).

\section{DISCUSSION}

Our method for the fabrication of porous scaffolds is based on the method described by Madihally and 


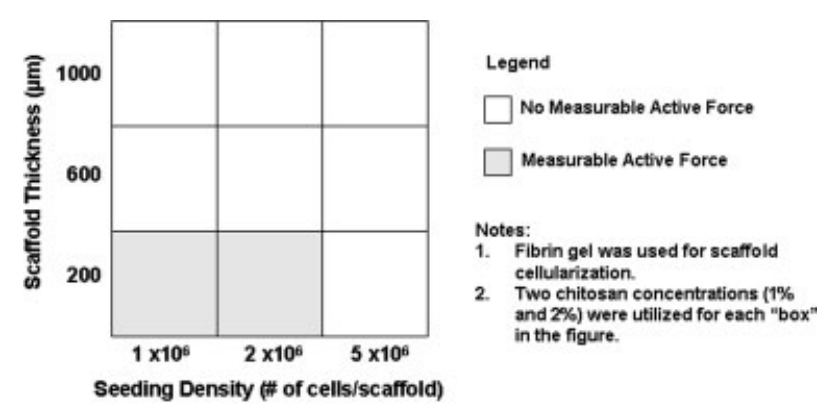

(a)

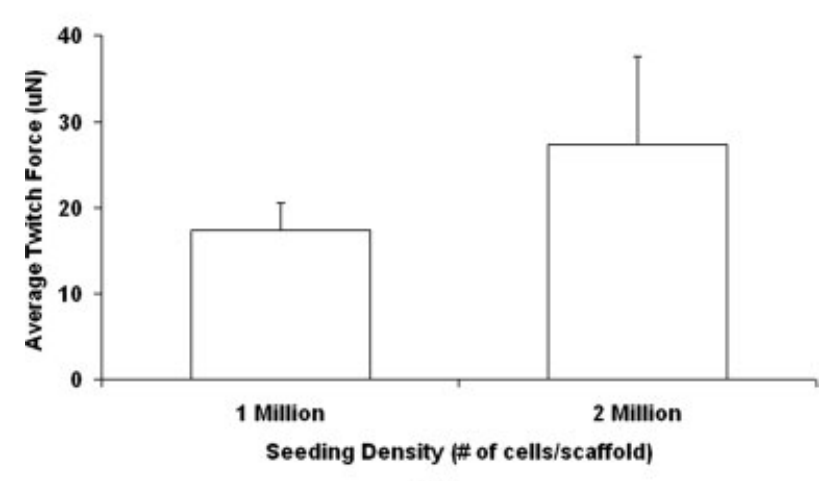

(b)

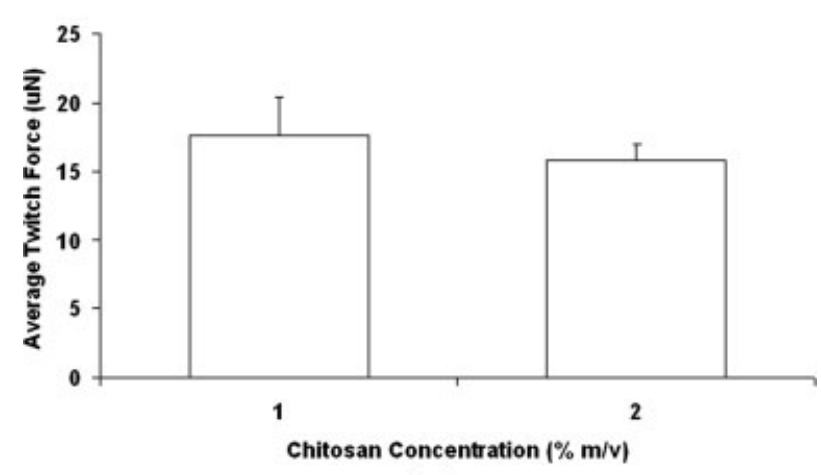

(c)

Figure 5. Effect of seeding density and polymer concentration. A: Parameter optimization-Three seeding densities $\left(1,2\right.$, and $5 \times 10^{6}$ cells / scaffold), three scaffold thicknesses $(200,600$, and $1000 \mu \mathrm{m})$, and two polymer concentrations ( 1 and $2 \%, w / v)$ were utilized for scaffold cellularization using fibrin gel as a support matrix. The active twitch force was evaluated 7 days after cellularization. Scaffolds cellularization using low-seeding densities $\left(1\right.$ and $\left.2 \times 10^{6}\right)$ at the lowest scaffold thickness $(200 \mu \mathrm{m})$ generated measurable active twitch force for both polymer concentrations tested ( 1 and $2 \%, w / v)$. B: Effect of cell number-There was no significant difference between the active twitch forces of scaffolds cellularized with $1 \times 10^{6}$ or $2 \times 10^{6}$ cells per scaffold. The scaffolds were fabricated utilizing $1 \%$ chitosan and a thickness of $200 \mu \mathrm{m}$. C: Effect of polymer concentration-There was no significant difference between the active twitch forces of cellularized scaffolds using either 1 or $2 \%$ chitosan. A seeding density of $1 \times 10^{6}$ cells per scaffold were used and a scaffold thickness of $200 \mu \mathrm{m}$.
Matthew. ${ }^{34}$ Using this method, chitosan polymer is solubilized in dilute glacial acetic acid, frozen and lyophilized to remove water crystals, resulting in pore formation. There are several variables that can be manipulated to optimize material properties for specific applications. The size of the pores is determined by the size of the water crystals, which in turn is dependant on the freezing temperature; a lower temperature results in small water crystals and a smaller pore size, as shown by Madihally and Matthew. ${ }^{34}$ Based on previously published work by Madihally and Matthew, ${ }^{34}$ we selected a specific pore size of $50 \mu \mathrm{m}$ and a freezing temperature of $-80^{\circ} \mathrm{C}$ as this has been shown to be the average pore diameter of neonatal cardiac myocytes. ${ }^{55}$ The pore diameter was validated utilizing scanning electron micrographs. We optimized the polymer concentration and the scaffold thickness for our applications. We determined that the lowest polymer concentration $(0.5 \%)$ resulted in the formation of fragile scaffolds while the highest polymer concentration $(3.0 \%)$ was not completely solubilized in acid. Our working range for polymer concentration was selected as $1.0 \%-2.5 \%$. We have not seen any other published studies looking at the polymer concentration, although it is likely that the specific range would vary based on application and vary depending on processing conditions. Scaffold thickness was found to be an important variable for cardiac applications. Fairly thick scaffolds, in excess of $600 \mu \mathrm{m}$ did not support the formation of contractile heart muscle, possibly due to nutrient deprivation of the cardiac cells. On the contrary, the thinnest scaffold we tested $(200 \mu \mathrm{m})$ proved to be the most suitable to support heart muscle formation. It is interesting to

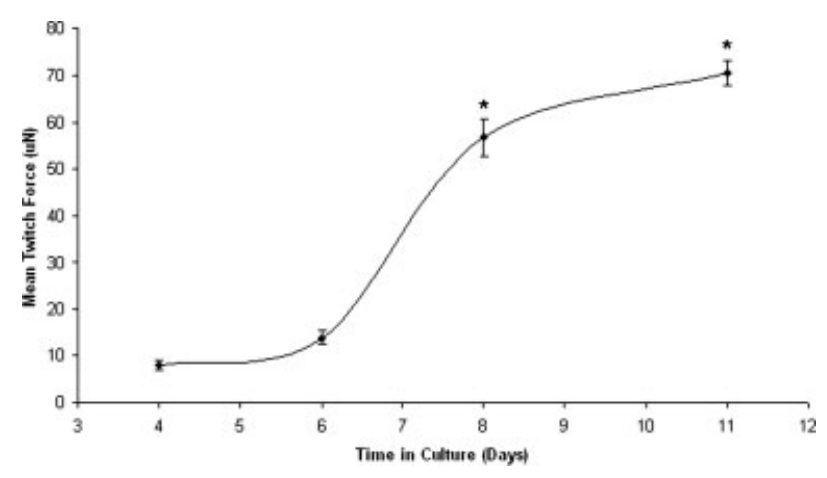

Figure 6. Changes in twitch force of cellularized scaffolds over Time. The average twitch of the constructs was evaluated at 4, 6, 8, and 11 days after cellularization. A total of three constructs were utilized for this study and five twitches obtained for each construct at every time point. The plot shows the average values and the error bars represent SEM. *Denotes a significant difference in the average twitch force with $p<0.05$. A polymer concentration of $1 \%$ and a scaffold thickness of $200 \mu \mathrm{m}$ was utilized with a plating density of 1 million cells. 
A. Cellularized Scaffolds

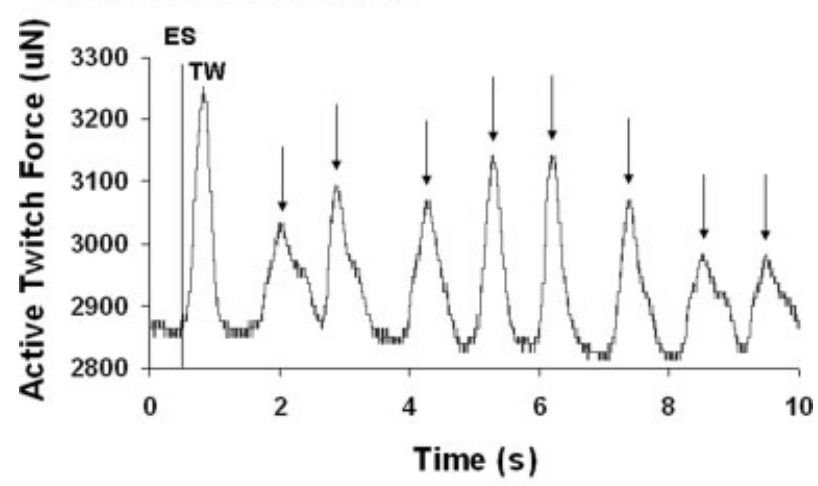

B. Control

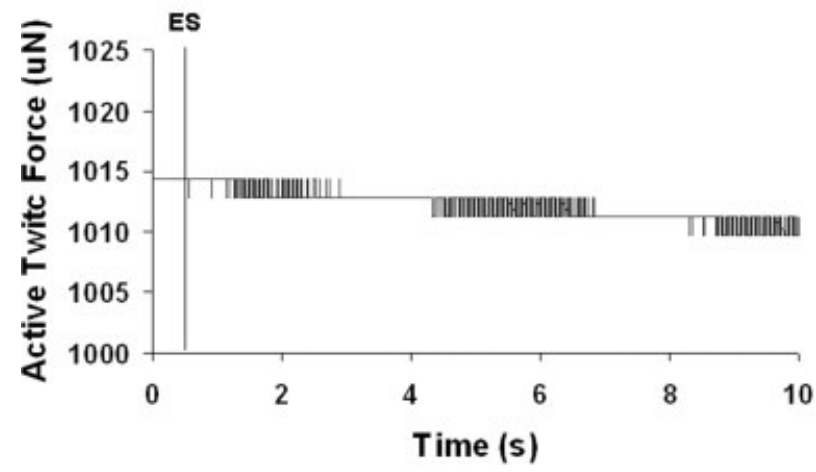

Figure 7. Representative twitch force tracing for the cellularized scaffolds. The constructs were electrically stimulated between parallel platinum electrodes. The stimulation parameters used were $10 \mathrm{~V}$ bipolar impulse with a pulse width of $10 \mathrm{~ms}$. The twitch force was recorded by attaching one end of the construct to the arm of an optical force transducer. A: Cellularized construct-The baseline force was found to be $2850 \mu \mathrm{N}$ and the maximum twitch force was found to be $439.5 \mu \mathrm{N}$. B: Controls-In the absence of cardiac cells, the scaffolds did not generate any measurable twitch force upon electrical stimulation. The baseline force was found to be $1014.3 \mu \mathrm{N}$. ES, electrical stimulus; TF, twitch force. Single arrows point to the spontaneous contractions of the construct. For both cases, a polymer concentration of $1 \%$ and a scaffold thickness of $200 \mu \mathrm{m}$ was utilized with a plating density of 1 million cells.

note that the scaffold thickness corresponds very well to the diffusion limit of oxygen in vitro, which has also be determined to be in the vicinity of $200 \mu \mathrm{m} .{ }^{56}$ We did not actually correlate the scaffold thickness to cell/construct viability, but rather empirically (based on twitch force) determined the working range for our applications. In concluding our discussion on material processing, we believe that our pilot studies helped us to define conditions that are most suited for our applications.

We evaluated the changes in scaffold performance by measuring the active force of constructs cellularized at different seeding densities; 1,2 , and 5 million cells per construct. This range was selected based on our findings with BEHM, utilizing fibrin gel. We found that very low cell numbers (less than 1 million cells/construct) and very high cell numbers (greater than 4 million cells/BEHM) produced fairly low active forces. BEHMs formed using the lower cell numbers did not have adequate contractile proteins, while BEHMs formed with higher cell numbers suffered nutrient deprivation. Our results with SMIHMs followed the same pattern. Very high seeding densities (12 million cells/SMIHM, data not shown) resulted in rapid scaffold degradation and presented a challenge to physically transfer such a large number of cells in a small volume of media, typically $50 \mu \mathrm{L}$ required for construct cellularization. Our results for the lower cell numbers, $1-5$ million, produced the best results, consistent with our findings in other tissue models that we have developed. The higher seeding densities (5 million cells/SMIHM) did not generate measurable force and was consistent with our findings in the BEHM model.

Our longevity studies showed that the active force of the SMIHMs gradually increased over a time

\section{A. Pacing at $3 \mathrm{~Hz}$}

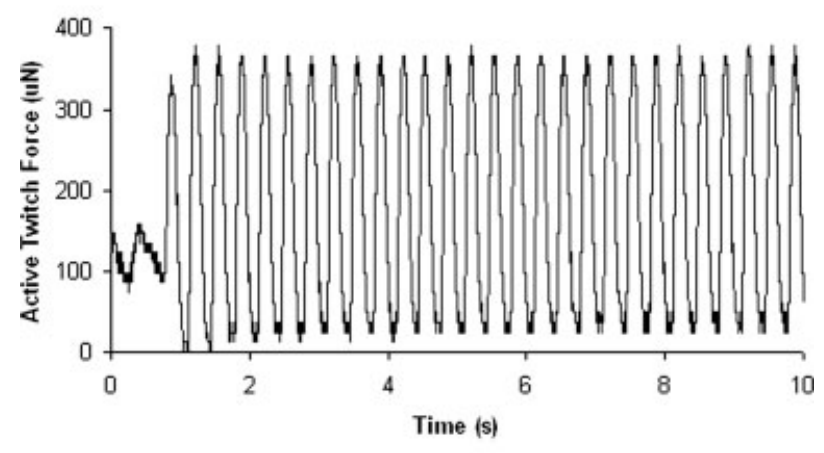

\section{B. Pacing at $5 \mathrm{~Hz}$}

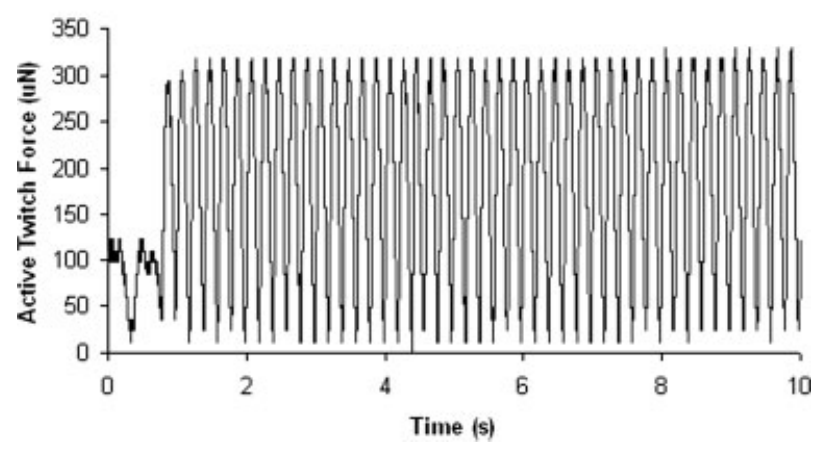

Figure 8. Electrical pacing of cellularized constructs. The constructs were electrically stimulated between parallel platinum electrodes using a voltage of $10 \mathrm{~V}$, pulse width of $10 \mathrm{~ms}$ and frequencies of (A) $3 \mathrm{~Hz}$ and (B) $5 \mathrm{~Hz}$. The baseline force for the constructs being paced at $3 \mathrm{~Hz}$ was found to be $1300 \mu \mathrm{N}$ and the maximum twitch force was found to be $378.4 \mu \mathrm{N}$, a polymer concentration of $1 \%$ and a scaffold thickness of $200 \mu \mathrm{m}$ was utilized with a plating density of 1 million cells. 
A. Twitch Force

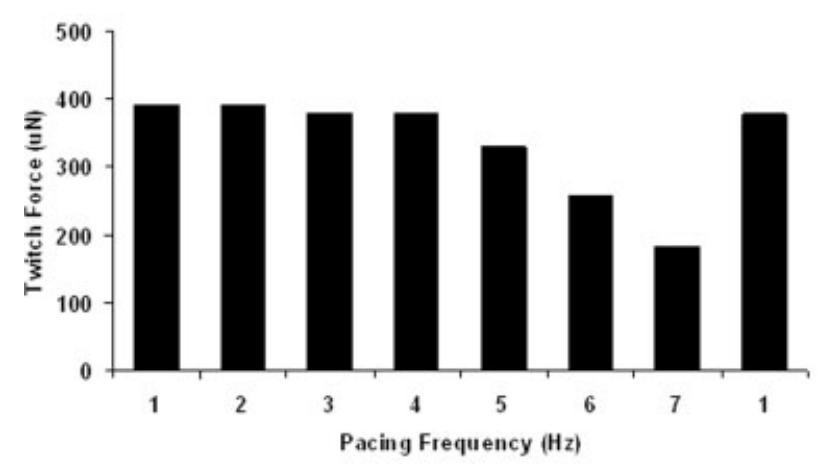

\section{B. Baseline Force}

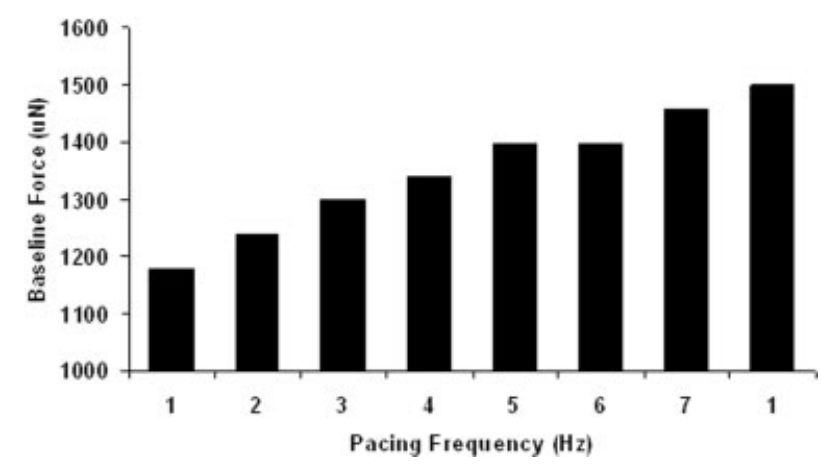

Figure 9. Effect of electrical pacing on the twitch force and baseline force. A: Twitch force-There was a decrease in the twitch force of the constructs when electrically paced at frequencies of $1-7 \mathrm{~Hz}$ in succession. The twitch force decreased from a value of $390.6 \mu \mathrm{N}$ at $1 \mathrm{~Hz}$ to a value of $183.1 \mu \mathrm{N}$ at $7 \mathrm{~Hz}$. However, the twitch force was restored to a value of $378.4 \mu \mathrm{N}$ after the constructs were allowed to rest for $10 \mathrm{~min}$ and then electrically paced at $1 \mathrm{~Hz}$. B: Baseline force-There was an increase in the baseline force with each pacing frequency tested, including a pacing frequency of $1 \mathrm{~Hz}$ after a $10-\mathrm{min}$ rest period. The baseline force increased from a value of $1177.8 \mu \mathrm{N}$ at $1 \mathrm{~Hz}$ to a value of $1458.6 \mu \mathrm{N}$ at $7 \mathrm{~Hz}$. This study was conducted for three constructs and the data shown were obtained from a single construct and is representative of the group.

period of 8-11 days and then started to decrease. The increase in active force is indicative of functional tissue remodeling and does provide some indirect measure of the ability of the scaffolding model to support the phenotypic maturation of primary cardiac cells. Detailed histological and biochemical characterizations would be required to determine the degree of tissue formation of the SMIHMs. The limited longevity beyond tissue maturation is somewhat troubling at this stage as we have not been able to maintain the active force of the SMIHMs beyond 2 weeks in culture. Optimization of the scaffold fabrication, cellularization methods, and culture conditions as well as development of micro-perfusion systems would be required to promote longevity of the SMIHMs in culture.
The ability to control the degradation kinetics of the chitosan scaffold is important. As tissue development and maturation takes place, the rate of scaffold degradation would need to be balanced with the rate of new tissue formation, necessitating accurate regulation of the degradation kinetics. Our results show that the rate of degradation of chitosan scaffolds can be modulated to promote complete scaffold degradation in time frames as short as $2 \mathrm{~h}$. The kinetics can also be regulated to promote slower degradation of the scaffold, often in the order of weeks.

The degradation kinetics of chitosan films have been reported by other groups. Lee fabricated thin films of chitosan (thickness of 40-60 $\mu \mathrm{m}$, dimension of $\left.10 \times 10 \mathrm{~mm}^{2}\right)^{42}$ and used lysozyme $(1 \mathrm{mg} / \mathrm{mL})$ to evaluate the degradation kinetics. It was shown that $20 \%$ of the film was degraded after $48 \mathrm{~h}$. In another study, Tomihata and Ikada ${ }^{39}$ fabricated chitosan films (thickness $150 \mu \mathrm{m}$ ) using varying degrees of de-acylation. After $50 \mathrm{~h}$ of lysozyme degradation $(4 \mathrm{mg} / \mathrm{mL}), 50 \%$ of the film was degraded with a degree of de-acylation of $69 \%$ and only $10 \%$ degradation was achieved with a degree of de-acylation of $90 \%$. Although the conditions described in these studies are not identical to the conditions in our study, the results are fairly comparable and show some general themes about the degradation of chitosan scaffolds/films. First, utilization of lysozyme is a fairly easy and effective method of promoting the degradation of chitosan scaffolds. ${ }^{37}$ Second, there are several variables that can be manipulated to modulate the degradation kinetics; these include the degree of de-acylation and substitution of the acetyl group with other side agents. Third, as we have shown in this study, the polymer percentage, the thickness of the scaffold and the concentration of the enzyme can have a profound effect on the degradation kinetics of the chitosan scaffolds.

The ability to carefully modulate the degradation kinetics of chitosan scaffolds would be useful for several potential applications in cardiac tissue engineering. First, the rate of scaffold degradation can be balanced to match the rate of new tissue formation by the primary cardiac cells. This is particularly interesting, permitting the formation of completely cellularized constructs in the absence of any synthetic scaffolding material prior to implantation; this can be accomplished by balancing the rate of collagen synthesis by the rate of scaffold degradation. This particular feature is our reasoning for terming the scaffolds as "smart materials". Second, cardioactive factors can be covalently linked to the chitosan polymer, permitting controlled release to allow phenotypic modulation of the cardiac cells during tissue formation. ${ }^{57,58}$ 
We evaluated two methods for scaffold cellularization with different functional outcomes. The first method was a simple strategy, involving direct injection of the primary cardiac cells on the surface of the scaffold. This method did not result in constructs that generated any measurable force upon electrical stimulation. Utilization of a fibrin gel had a positive effect on the functional performance of the constructs. There are several interesting points to consider regarding this study. Firstly, chitosan is a commercially available "off-the-shelf" polymer that we evaluated to support cardiac cell remodeling. The inability of the chitosan to support cardiac cell attachment directly after cell injection demonstrates the lack of functional interaction points with chitosan. This means that the cardiac cells may not be forming a physiological bond with the chitosan, possibly due to the lack of integrin-binding sites. It would be necessary to engineer bio-mimetic activity within the polymer backbone of chitosan to promote functional interaction with primary cardiac cells. Several studies have shown that this is a feasible option as chitosan has multiple functional sites, amine and hydroxyl, which can be covalently linked to bioactive factors. Moreover, the inability of the cardiac cells to functionally interact with chitosan demonstrates the need to develop novel biomaterials specifically targeted for cardiac tissue engineering applications, a reoccurring theme in the field of functional tissue engineering. ${ }^{59,60}$

To overcome some of the difficulties in working with chitosan, we sought to use fibrin as a support matrix during construct formation. The utilization of fibrin resulted in the formation of $3 \mathrm{D}$ tissue engineered constructs. The incorporation of fibrin into our scaffold-based model does lead to an interesting dimension. The degradation kinetics of the fibrin can be manipulated, independent of the degradation of the chitosan.

There has only been one other group utilizing polymeric scaffolds to engineer functional heart muscle. Freed and coworkers utilize polyglycolic acid (PGA) as the scaffolding materials with direct cell injection being utilized for cellularization. ${ }^{24,25}$ Although a high degree of cellularization has been demonstrated, contractile performance has not been reported. ${ }^{24,25,61}$ The work by this group clearly demonstrates that biomaterials can be cellularized in the absence of carriers, like fibrin. Although PGA has been shown to support functional remodeling of primary cardiac cells, chitosan lacks this functionality in its commercially available unmodified form. As more biomaterials are evaluated for cardiac tissue engineering applications, each material will need to be developed based on its specific properties; it would be difficult to make generalizations about the suitability of any biomaterial to support cardiac cell remodeling. Biomaterials would need to be evaluated on a case-by-case basis and process to meet the needs of specific applications.

SMIHMs generated active force upon electrical stimulation. The maximum twitch force was found to be $439.5 \mu \mathrm{N}$ with a specific force of $0.44 \mathrm{kN} / \mathrm{m}^{2}$. Our previous two models of heart muscle tissue in vitro, cardioids, ${ }^{27}$ and BEHMs, ${ }^{30}$ have shown to generate considerably higher specific forces than the current model. Cardioids generate an average specific force of $2-4 \mathrm{kN} / \mathrm{m}^{2}$ while the specific force of BEHMs has been shown to be as high as $12-15 \mathrm{kN} /$ $\mathrm{m}^{2}{ }^{27,30}$ The twitch force of cardioids is in the range of $200-300 \mu \mathrm{N}$ and $600-800 \mu \mathrm{N}$ for BEHMs and the cross-sectional area of both cardioids and BEHMs in the range of $200-300 \mu \mathrm{m}$.

The specific force of the SMIHMs is significantly lower than the specific force for our other two models. This could be due to the fact that that chitosan is not functionally interacting with the primary cardiac cells. Our speculation is based on the inability of the cellularized chitosan scaffold to generate measurable forces in the absence of fibrin gel. The more likely scenario at this stage is that the scaffold is serving as a nonfunctional carrier of the cardiac myocytes. Modification of the material, possibly by fabricating scaffolds with collagen or covalently linking adhesion peptides, may provide increased functionality.

Eschenhagen and coworkers ${ }^{15}$ developed a model of 3D heart muscle using collagen gel as the support matrix and the resulting heart muscle shows fairly high contractile forces. The work compares well with our BEHM model in terms of contractile performance, while the contractile forces of our current model are considerably lower. The similarity between our BEHM model and the work by Eschenhagen and coworkers is in the utilization of biodegradable hydrogels to support the formation of functional tissue engineered heart muscle; we utilized fibrin while Eschenhagen used collagen type I. Hydrogels, in general have been shown to support heart muscle formation; at least based on current technology.

Okanos and coworkers' model ${ }^{22}$ compares well with our cardioid model; both based on the self-organization of primary cardiac cells. The similarity is mainly methodological, whereby functional 3D heart muscle constructs are generated in the absence of scaffolding material. Okano and coworkers utilized temperature-sensitive polymers to promote the detachment of a cohesive monolayer of cardiac cells while we utilized surface concentration of adhesion proteins for monolayer delamination.

Freeds and coworkers utilized PGA to support the formation of heart muscle and have shown several physiological performance metrics in terms of histological and biochemical characterization. ${ }^{25}$ Our 
model seems to compare well with the model published by Freeds and coworkers in terms of demonstrating the ability of polymeric scaffolds to support the functional remodeling of primary cells. The similarity between our SMIHM model and the work by Freed and coworkers is the utilization of polymeric scaffold followed by cellularization with primary cardiac cells.

In addition to evaluating the active force, we evaluated the baseline force and the pacing characteristics of the SMIHMs. The baseline force of the SMHIMs were considerably higher than the baseline force for cardioids ${ }^{27}$ and BEHMs. ${ }^{30}$ This was somewhat expected due to the rigidity of the chitosan scaffold and its ability to generate baseline tension, even in an un-stimulated state. More interesting was the increase in baseline force in response to electrical stimulation. This was particularly evident in the studies with variations in the pacing frequency; increasing the pacing frequency resulted in an increase in the baseline force. We also observed a decrease in the active force of the SMHIMs in response to increased electrical pacing. Recovery of force after a period of rest indicated that the muscle cells did not undergo physical damage during the electrical stimulations and induced contractions.

The authors thank Dr. M. Welsh, Associate Chair of the Department of Molecular and Cell Biology at the University of Michigan for donating a lyophilizer that was utilized extensively in this project.

\section{References}

1. Chapekar MS. Tissue engineering: Challenges and opportunities [Review]. J Biomed Mater Res 2000;53:617-620.

2. Fuchs JR, Nasseri BA, Vacanti JP. Tissue engineering: A 21st century solution to surgical reconstruction [Review]. Ann Thorac Surg 2001;72:577-591.

3. Lysaght MJ, Reyes J. The growth of tissue engineering [Review]. Tissue Eng 2001;7:485-493.

4. Naito H, Takewa Y, Mizuno T, Ohya S, Nakayama Y, Tatsumi E, Kitamura S, Takano H, Taniguchi S, Taenaka Y. Three-dimensional cardiac tissue engineering using a thermoresponsive artificial extracellular matrix. ASAIO J 2004; 50:344-348

5. Zammaretti P, Jaconi M. Cardiac tissue engineering: Regeneration of the wounded heart [Review]. Curr Opin Biotechnol 2004;15:430-434.

6. Alperin C, Zandstra PW, Woodhouse KA. Polyurethane films seeded with embryonic stem cell-derived cardiomyocytes for use in cardiac tissue engineering applications. Biomaterials 2005;26:7377-7386.

7. Park H, Radisic M, Lim JO, Chang BH, Vunjak-Novakovic G. A novel composite scaffold for cardiac tissue engineering. In Vitro Cell Dev Biol Anim 2005;41:188-196.

8. Radisic M, Park H, Chen F, Salazar-Lazzaro JE, Wang Y, Dennis R, Langer R, Freed LE, Vunjak-Novakovic G. Biomimetic approach to cardiac tissue engineering: Oxygen carriers and channeled scaffolds. Tissue Eng 2006;12:20772091.
9. Morritt AN, Bortolotto SK, Dilley RJ, Han X, Kompa AR, McCombe D, Wright CE, Itescu S, Angus JA, Morrison WA. Cardiac tissue engineering in an in vivo vascularized chamber. Circulation 2007;115:353-360.

10. Macfelda K, Kapeller B, Wilbacher I, Losert UM. Behavior of cardiomyocytes and skeletal muscle cells on different extracellular matrix components-Relevance for cardiac tissue engineering. Artif Organs 2007;31:4-12.

11. van Luyn MJ, Tio RA, van Seijen XJ, Plantinga JA, de Leij LF, DeJongste MJ, van Wachem PB. Cardiac tissue engineering: Characteristics of in unison contracting two- and threedimensional neonatal rat ventricle cell (co)-cultures. Biomaterials 2002;23:4793-4801.

12. Kofidis T, Akhyari P, Wachsmann B, Boublik J, Mueller-Stahl K, Leyh R, Fischer S, Haverich A. A novel bioartificial myocardial tissue and its prospective use in cardiac surgery. Eur J Cardiothorac Surg 2002;22:238-243.

13. Dar A, Shachar M, Leor J, Cohen S. Optimization of cardiac cell seeding and distribution in 3D porous alginate scaffolds. Biotechnol Bioeng 2002;80:305-312.

14. Ozawa T, Mickle DA, Weisel RD, Koyama N, Ozawa S, Li RK. Optimal biomaterial for creation of autologous cardiac grafts. Circulation 2002;106(Suppl 82). p 176-182.

15. Eschenhagen T, Fink C, Remmers U, Scholz H, Wattchow J, Weil J, Zimmermann W, Dohmen HH, Schafer H, Bishopric $\mathrm{N}$, Wakatsuki T, Elson EL. Three-dimensional reconstitution of embryonic cardiomyocytes in a collagen matrix: A new heart muscle model system. FASEB J 1997;11:683-694.

16. Zimmermann WH, Fink C, Kralisch D, Remmers U, Weil J, Eschenhagen T. Three-dimensional engineered heart tissue from neonatal rat cardiac myocytes. Biotechnol Bioeng 2000; 68:106-114.

17. Kofidis $\mathrm{T}$, Akhyari $\mathrm{P}$, Boublik J, Theodorou P, Martin U, Ruhparwar A, Fischer S, Eschenhagen T, Kubis HP, Kraft T, Leyh R, Haverich A. In vitro engineering of heart muscle: Artificial myocardial tissue. J Thorac Cardiovasc Surg 2002;124: 63-69.

18. Eschenhagen T, Didie M, Munzel F, Schubert P, Schneiderbanger $\mathrm{K}$, Zimmermann WH. 3D engineered heart tissue for replacement therapy. Basic Res Cardiol 2002;97(Suppl 52). p 146-152.

19. Li RK, Yau TM, Weisel RD, Mickle DA, Sakai T, Choi A, Jia ZQ. Construction of a bioengineered cardiac graft. J Thorac Cardiovasc Surg 2000;119:368-375.

20. Leor J, Aboulafia-Etzion S, Dar A, Shapiro L, Barbash IM, Battler A, Granot Y, Cohen S. Bioengineered cardiac grafts: A new approach to repair the infarcted myocardium? Circulation 2000;102(Suppl 61). p 56-61.

21. Akins RE, Boyce RA, Madonna ML, Schroedl NA, Gonda SR, McLaughlin TA, Hartzell CR. Cardiac organogenesis in vitro: Reestablishment of three-dimensional tissue architecture by dissociated neonatal rat ventricular cells. Tissue Eng 1999; 5:103-118.

22. Shimizu T, Yamato M, Isoi $Y$, Akutsu T, Setomaru T, Abe K, Kikuchi A, Umezu M, Okano T. Fabrication of pulsatile cardiac tissue grafts using a novel 3-dimensional cell sheet manipulation technique and temperature-responsive cell culture surfaces. Circ Res 2002;90:e40.

23. Bursac N, Papadaki M, Cohen RJ, Schoen FJ, Eisenberg SR, Carrier R, Vunjak-Novakovic G, Freed LE. Cardiac muscle tissue engineering: Toward an in vitro model for electrophysiological studies. Am J Physiol 1999;277:t-44.

24. Papadaki M, Bursac N, Langer R, Merok J, Vunjak-Novakovic $\mathrm{G}$, Freed LE. Tissue engineering of functional cardiac muscle: Molecular, structural, and electrophysiological studies. Am J Physiol Heart Circ Physiol 2001;280:H168-H178.

25. Carrier RL, Papadaki M, Rupnick M, Schoen FJ, Bursac N, Langer R, Freed LE, Vunjak-Novakovic G. Cardiac tissue en- 
gineering: Cell seeding, cultivation parameters, and tissue construct characterization. Biotechnol Bioeng 1999;64:580-589.

26. Li RK, Jia ZQ, Weisel RD, Mickle DA, Choi A, Yau TM. Survival and function of bioengineered cardiac grafts. Circulation 1999;100(Suppl 9). p 63-69.

27. Baar K, Birla R, Boluyt MO, Borschel GH, Arruda EM, Dennis RG. Self-organization of rat cardiac cells into contractile 3-D cardiac tissue. FASEB J 2005;19(2):275-277.

28. Birla RK, Borschel GH, Dennis RG, Brown DL. Myocardial engineering in vivo: Formation and characterization of contractile, vascularized three-dimensional cardiac tissue. Tissue Eng 2005;11:803-813.

29. Birla RK, Borschel GH, Dennis RG. In vivo conditioning of tissue-engineered heart muscle improves contractile performance. Artif Organs 2005;29:866-875.

30. Huang YC, Khait L, Birla RK. Contractile three-dimensional bioengineered heart muscle for myocardial regeneration. J Biomed Mater Res 2007;80A:719-731.

31. Boublik J, Park H, Radisic M, Tognana E, Chen F, Pei M, Vunjak-Novakovic G, Freed LE. Mechanical properties and remodeling of hybrid cardiac constructs made from heart cells, fibrin, and biodegradable, elastomeric knitted fabric. Tissue Eng 2005;11:1122-1132.

32. Ye Q, Zund G, Benedikt P, Jockenhoevel S, Hoerstrup SP, Sakyama S, Hubbell JA, Turina M. Fibrin gel as a three dimensional matrix in cardiovascular tissue engineering. Eur J Cardiothorac Surg 2000;17:587-591.

33. Khor E, Lim LY. Implantable applications of chitin and chitosan [Review]. Biomaterials 2003;24:2339-2349.

34. Madihally SV, Matthew HW. Porous chitosan scaffolds for tissue engineering. Biomaterials 1920:1133-1142.

35. Mi FL, Shyu SS, Wu YB, Lee ST, Shyong JY, Huang RN. Fabrication and characterization of a sponge-like asymmetric chitosan membrane as a wound dressing. Biomaterials 2001;22:165-173.

36. Sechriest VF, Miao YJ, Niyibizi C, Westerhausen-Larson A, Matthew HW, Evans CH, Fu FH, Suh JK. GAG-augmented polysaccharide hydrogel: A novel biocompatible and biodegradable material to support chondrogenesis. J Biomed Mater Res 2000;49:534-541.

37. Suh JK, Matthew HW. Application of chitosan-based polysaccharide biomaterials in cartilage tissue engineering: A review. Biomaterials 2000;21:2589-2598.

38. Muzzarelli RA. Human enzymatic activities related to the therapeutic administration of chitin derivatives [Review]. Cell Mol Life Sci 1997;53:131-140.

39. Tomihata K, Ikada Y. In vitro and in vivo degradation of films of chitin and its deacetylated derivatives. Biomaterials 1997;18:567-575.

40. VandeVord PJ, Matthew HW, DeSilva SP, Mayton L, Wu B, Wooley PH. Evaluation of the biocompatibility of a chitosan scaffold in mice. J Biomed Mater Res 2002;59:585-590.

41. Onishi H, Machida Y. Biodegradation and distribution of water-soluble chitosan in mice. Biomaterials 1920;20(2):175-182.

42. Lee KY, Ha WS, Park WH. Blood compatibility and biodegradability of partially $\mathrm{N}$-acylated chitosan derivatives. Biomaterials 1995;16:1211-1216.

43. Ma J, Wang H, He B, Chen J. A preliminary in vitro study on the fabrication and tissue engineering applications of a novel chitosan bilayer material as a scaffold of human neofetal dermal fibroblasts. Biomaterials 2001;22:331-336.

44. Itoh S, Suzuki M, Yamaguchi I, Takakuda K, Kobayashi H, Shinomiya K, Tanaka J. Development of a nerve scaffold using a tendon chitosan tube. Artif Organs 2003;27:10791088.

45. Zhang $\mathrm{Y}$, Zhang M. Synthesis and characterization of macroporous chitosan/calcium phosphate composite scaffolds for tissue engineering. J Biomed Mater Res 2001;55:304-312.

46. Zhang Y, Zhang M. Three-dimensional macroporous calcium phosphate bioceramics with nested chitosan sponges for load-bearing bone implants. J Biomed Mater Res 2002;61:1-8.

47. Zhang Y, Ni M, Zhang M, Ratner B. Calcium phosphate-chitosan composite scaffolds for bone tissue engineering. Tissue Eng 2003;9:337-345.

48. Chung TW, Yang J, Akaike T, Cho KY, Nah JW, Kim SI, Cho CS. Preparation of alginate/galactosylated chitosan scaffold for hepatocyte attachment. Biomaterials 2002;23:28272834.

49. Park IK, Yang J, Jeong HJ, Bom HS, Harada I, Akaike T, Kim SI, Cho CS. Galactosylated chitosan as a synthetic extracellular matrix for hepatocytes attachment. Biomaterials 2003;24: 2331-2337.

50. Yang J, Chung TW, Nagaoka M, Goto M, Cho CS, Akaike T. Hepatocyte-specific porous polymer-scaffolds of alginate/galactosylated chitosan sponge for liver-tissue engineering. Biotechnol Lett 2001;23:1385-1389.

51. Cui W, Kim DH, Imamura M, Hyon SH, Inoue K Tissueengineered pancreatic islets: Culturing rat islets in the chitosan sponge. Cell Transplant 2001;10:499-502.

52. Yeo Y, Burdick JA, Highley CB, Marini R, Langer R, Kohane DS. Peritoneal application of chitosan and UV-cross-linkable chitosan. J Biomed Mater Res A 2006;78:668-675.

53. Fujita M, Ishihara M, Morimoto $Y$, Simizu M, Saito $Y$, Yura H, Matsui T, Takase B, Hattori H, Kanatani Y, Kikuchi M, Maehara T. Efficacy of photocrosslinkable chitosan hydrogel containing fibroblast growth factor-2 in a rabbit model of chronic myocardial infarction. J Surg Res 2005;126:27-33.

54. Boluyt MO, Zheng JS, Younes A, Long X, O'Neill L, Silverman H, Lakatta EG, Crow MT. Rapamycin inhibits $\alpha 1$-adrenergic receptor-stimulated cardiac myocyte hypertrophy but not activation of hypertrophy-associated genes. Evidence for involvement of p70 S6 kinase. Circ Res 1997;81:176-186.

55. Clubb FJ Jr, Bishop SP. Formation of binucleated myocardial cells in the neonatal rat. An index for growth hypertrophy. Lab Invest 1984;50:571-577.

56. Colton CK. Implantable biohybrid artificial organs [Review]. Cell Transplant 1995;4:415-436.

57. Ehrbar M, Djonov VG, Schnell C, Tschanz SA, Martiny-Baron G, Schenk U, Wood J, Burri PH, Hubbell JA, Zisch AH. Celldemanded liberation of VEGF121 from fibrin implants induces local and controlled blood vessel growth. Circ Res 2004;94:1124-1132.

58. Zisch AH, Lutolf MP, Ehrbar M, Raeber GP, Rizzi SC, Davies N, Schmokel H, Bezuidenhout D, Djonov V, Zilla P, Hubbell JA. Cell-demanded release of VEGF from synthetic, biointeractive cell ingrowth matrices for vascularized tissue growth. FASEB J 2003;17:2260-2262.

59. Davis ME, Hsieh PC, Grodzinsky AJ, Lee RT. Custom design of the cardiac microenvironment with biomaterials [Review]. Circ Res 2005;97:8-15.

60. Rosso F, Marino G, Giordano A, Barbarisi M, Parmeggiani D, Barbarisi A. Smart materials as scaffolds for tissue engineering [Review]. J Cell Physiol 2005;203:465-470.

61. Radisic M, Euloth M, Yang L, Langer R, Freed LE, VunjakNovakovic G. High-density seeding of myocyte cells for cardiac tissue engineering. Biotechnol Bioeng 2003;82:403-414. 